\title{
Assessment of Agricultural Water Requirements for Semi-Arid Areas: A Case Study of the Boufakrane River Watershed (Morocco)
}

\author{
Mohammed El Hafyani ${ }^{1, *(D)}$, Ali Essahlaoui ${ }^{1}$, Kimberley Fung-Loy ${ }^{2,3}$ (D) Jason A. Hubbart ${ }^{4,5,6}$ \\ and Anton Van Rompaey ${ }^{2}$ iD
}

1 Department of Geology, Laboratory of Geoengineering and Environment, Research Group “Water Sciences and Environment Engineering", Faculty of Sciences, Moulay Ismail University, Zitoune,

Meknes BP11201, Morocco; a.essahlaoui@fs-umi.ac.ma

2 Department of Earth and Environmental Sciences, Geography and Tourism Research Group, KU Leuven, Celestijnenlaan 200E, 3001 Heverlee, Belgium; kimberley.fung-loy@uvs.edu (K.F.-L.); anton.vanrompaey@kuleuven.be (A.V.R.)

3 Department of Sustainable Management of Natural Resources, Anton de Kom University of Suriname, Paramaribo, Suriname

4 Institute of Water Security and Science, West Virginia University, 3109 Agricultural Sciences Building, Morgantown, WV 26506, USA; jason.hubbart@mail.wvu.edu

5 Division of Plant and Soil Sciences, Davis College of Agriculture, Natural Resources and Design, West Virginia University, Agricultural Sciences Building, Morgantown, WV 26506, USA

\section{check for} updates

Citation: El Hafyani, M.; Essahlaoui, A.; Fung-Loy, K.; Hubbart, J.A.; Van Rompaey, A. Assessment of Agricultural Water Requirements for Semi-Arid Areas: A Case Study of the Boufakrane River Watershed (Morocco). Appl. Sci. 2021, 11, 10379. https://doi.org/10.3390/ app112110379

Academic Editors: Dimitrios S. Paraforos and Manuel Armada

Received: 27 August 2021

Accepted: 26 October 2021

Published: 5 November 2021

Publisher's Note: MDPI stays neutral with regard to jurisdictional claims in published maps and institutional affiliations.

Copyright: (c) 2021 by the authors. Licensee MDPI, Basel, Switzerland. This article is an open access article distributed under the terms and conditions of the Creative Commons Attribution (CC BY) license (https:// creativecommons.org/licenses/by/ $4.0 /)$.
6 Division of Forestry and Natural Resources, Davis College of Agriculture, Natural Resources and Design, West Virginia University, Agricultural Sciences Building, Morgantown, WV 26506, USA

* Correspondence: m.elhafyani@edu.umi.ac.ma

Abstract: This work was undertaken to develop a low-cost but reliable assessment method for agricultural water requirements in semi-arid locations based on remote sensing data/techniques. In semi-arid locations, water resources are often limited, and long-term water consumption may exceed the natural replenishment rates of groundwater reservoirs. Sustainable land management in these locations must include tools that facilitate assessment of the impact of potential future land use changes. Agricultural practices in the Boufakrane River watershed (Morocco) were used as a case study application. Land use practices were mapped at the thematic resolution of individual crops, using a total of 13 images generated from the Sentinel-2 satellites. Using a supervised classification scheme, crop types were identified as cereals, other crops followed by cereals, vegetables, olive trees, and fruit trees. Two classifiers were used, namely Support vector machine (SVM) and Random forest (RF). A validation of the classified parcels showed a high overall accuracy of $89.76 \%$ for SVM and $84.03 \%$ for RF. Results showed that cereal is the most represented species, covering 8870.43 ha and representing $52.42 \%$ of the total area, followed by olive trees with 4323.18 ha and a coverage rate of $25 \%$. Vegetables and other crops followed by cereals cover 1530.06 ha and 1661.45 ha, respectively, representing $9.4 \%$ and $9.8 \%$ of the total area. In the last rank, fruit trees occupy only $3.67 \%$ of the total area, with 621.06 ha. The Food and Agriculture Organization (FAO) free software was used to overlay satellite data images with those of climate for agricultural water resources management in the region. This process facilitated estimations of irrigation water requirements for all crop types, taking into account total potential evapotranspiration, effective rainfall, and irrigation water requirements. Results showed that olive trees, fruit trees, and other crops followed by cereals are the most water demanding, with irrigation requirements exceeding $500 \mathrm{~mm}$. The irrigation requirements of cereals and vegetables are lower than those of other classes, with amounts of $300 \mathrm{~mm}$ and $150 \mathrm{~mm}$, respectively.

Keywords: Sentinel-2; SVM; RF; Boufakrane River watershed; irrigation requirements; water resources; sustainable land use; agriculture 


\section{Introduction}

According to World Bank data, the global rural population declined from $66.39 \%$ of the total population in 1960 to $44.72 \%$ in 2016. Meanwhile, agricultural added value, as a percentage of GDP (gross domestic product), decreased from 7.59 to $3.43 \%$ during the period 1994-2017. Despite these changes, the continued growth of the global human population has resulted in phases of deforestation together with innovations, increasing the efficiency of agricultural systems, and subsequent crises of unprecedented demographic, economic and urban expansion [1,2].

In semi-arid regions like Morocco, agricultural practices are facing a series of challenges not limited to climate change, which is reflected in an increasingly warmer and drier climate [3], coupled with the increasingly random spatiotemporal variability of rainfall, and associated droughts and floods [4-8]. These issues are exacerbated by increasingly complex land use and land cover practices that in turn adversely affect socio-economic development [9]. Agriculture, as an important economic sector, is therefore deeply impacted, given crop production dependence on the annual rainfall distribution [4-8]. It is clear that humans have created and are now witnessing a great agricultural ecosystem disturbance [8].

Recently, geospatial technologies have been used extensively for spatiotemporal monitoring of environmental phenomena, including land use/land cover changes [6,9-15], understanding the ecosystem functions [16,17], identifying agricultural systems and crop mapping [3,8,18,19], estimating fractional crop cover and crop residue [20], estimating the impacts of urbanization on agricultural dynamics [3], identifying the karst cavities in agricultural areas [21-23], and water balance assessments at regional and local scales [6,24]. Many investigations have shown a great deal of potential in terms of different machine learning approaches in imagery classification, such as vector machine support [3,25-29] and random forest [30-32]. These innovative data interrogation and modeling approaches are critically important for estimating agricultural crop water use. This is important in order to implement effective strategies for advanced water resource management for agriculture in response to contemporary water budget challenges. Several works have been published supporting these needs in recent years [33-41], particularly in semi-arid zones [42]. Ofentse Moseki et al. [42] used the CROPWAT model to determine the irrigation needs of the Jatropha crop in Botswana. They used the CROPWAT model to estimate baseline evapotranspiration (ETo), evapotranspiration (ETc), irrigation water requirements (IWR) and yield response to irrigation scheduling in Botswana. The results showed that the annual ETo from 2014 to 2016 at the station was $1456 \mathrm{~mm}$. The lowest monthly ETo $(50.10 \mathrm{~mm})$ was observed in June and the highest $(182.59 \mathrm{~mm})$ in January.

This model is widely used, especially in understanding the changes in crop water requirements [38], which are defined as the depth of water required to meet the evapotranspiration water loss (ETc) of a disease-free crop growing in large fields; this parameter is important for promoting sustainable development. In particular, the model is used in the determination of crop water and of the effects of irrigation programming on the crop [40,41]. This model allows calculation of the water requirements of the different crops using soil data, climatic data, and data on the crops themselves. Therefore, to determine the crop's water requirement, several parameters were calculated.

Calculation of Potential Evaporation of Crop ETc: Before calculating the ETc, specific studies on the water requirements of crops in the area should be examined; the meteorological and research stations and the environment should also be visited. The calculation of this parameter is done by the following two main steps:

(a) Reference evapotranspiration ( $\left.E T_{0}\right)$ : Collect climate data and choose the method for calculating $\mathrm{ET}_{0}$ for each 30 or 10 day period using the average climate data.

(b) Crop coefficient $(\mathrm{kc})$ : Determine the timing of planting or sowing, the rate of crop development, the duration of crop development stages and the growing season. Choose the kc for a given crop plan and crop development stage under prevailing climatic conditions, and prepare a crop coefficient curve for each one.

(c) Crop evapotranspiration (ETcrop): Calculate ETcrop for each 30- or 10-day period: 


$$
E T c=K c * E T_{0}
$$

Irrigation requirements: Part of the crop water requirements is met by rainfall $(\mathrm{Pe})$, groundwater $(\mathrm{Ge})$ and stored soil water $(\mathrm{Wb})$; or

$$
I r r . R e q=E T c-P e-G e-W b
$$

and is determined on a monthly basis.

The specific objectives of this work were to (i) use high spatial resolution Sentinel-2 images to map crop types in the Boufakrane watershed; (ii) evaluate machine learning (ML) methods such as support vector machine (SVM) classifier and random forest (RF) in crop species' mapping; (iii) use the CROPWAT 8.0 model to estimate water demand for agriculture in the study area through the calculation of potential evaporation and effective rainfall. Finally, irrigation water requirements were estimated.

\section{Materials and Methods}

\subsection{Study Area}

The Boufakrane River watershed is located in the headwaters region of the Great Sebou Basin between longitudes $5^{\circ} 25^{\prime} 46.13^{\prime \prime}$ and $5^{\circ} 37^{\prime} 49.71^{\prime \prime} \mathrm{W}$ and between latitudes $33^{\circ} 28^{\prime} 54.40^{\prime \prime}$ and $33^{\circ} 58^{\prime} 32.93^{\prime \prime} \mathrm{N}$ (Figure 1). Locally, the area is part of the Fez-Meknes region, which is one of the most important and productive areas for agriculture in the region, given its relatively high water availability and good quality soils. The regional Useful Agricultural Area (UAA) is estimated to be approximately 1,340,826 hectares, representing $15 \%$ of the national total area. The UAA is dominated by cereals $(816,000 \mathrm{ha})$ and olive trees (350,000 ha), and $14 \%$ of the area is irrigated (184,162 ha). Climatically, the region is characterized by a semi-arid climate, with a mean annual rainfall of $500 \mathrm{~mm}$, a mean annual reference evapotranspiration of $907 \mathrm{~mm}$, and a dry season extending from June to October (Figure 2).
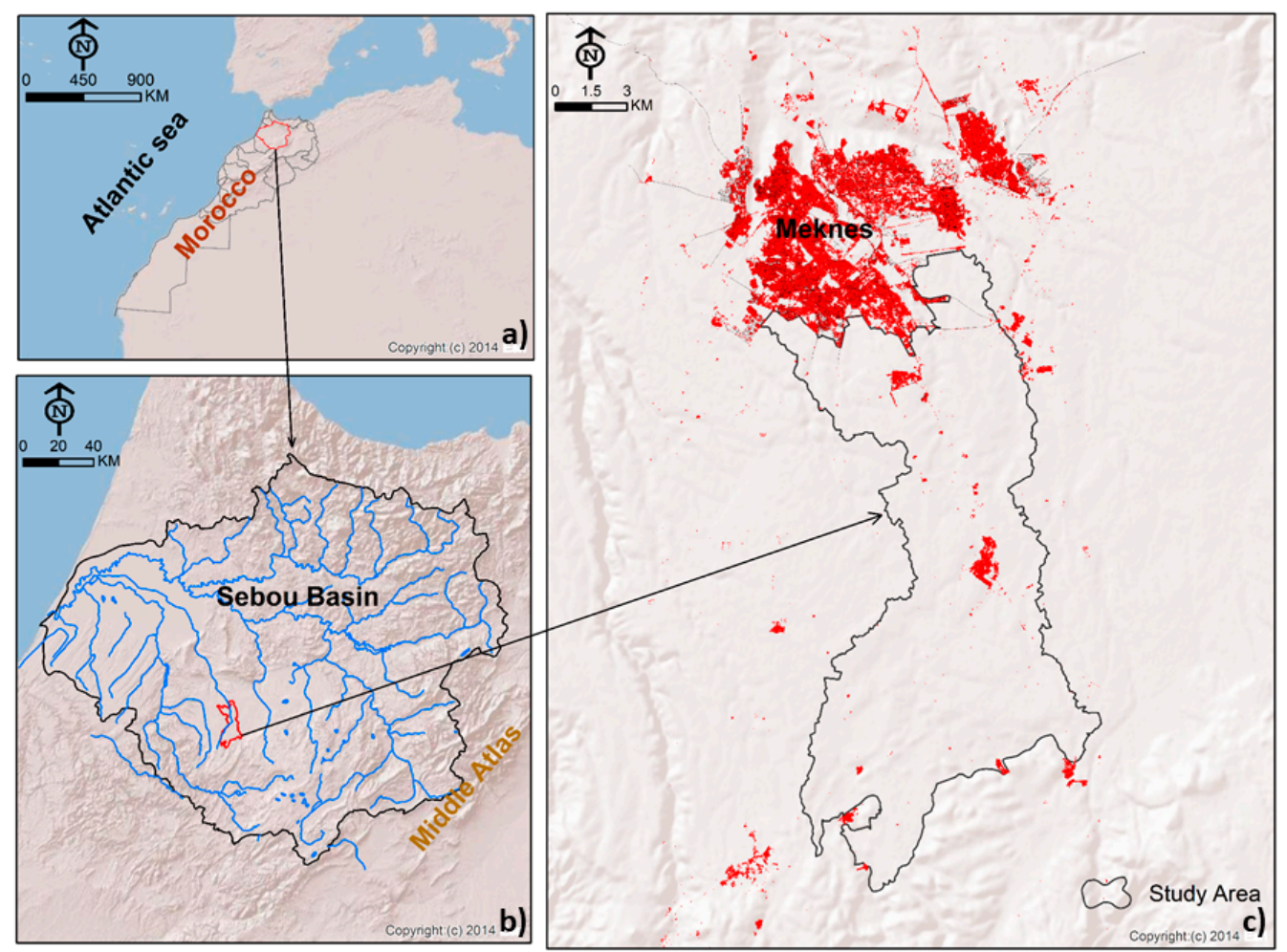

Figure 1. Study area: (a) Kingdom of Morocco, (b) Sebou Basin, (c) Boufakrane watershed. 


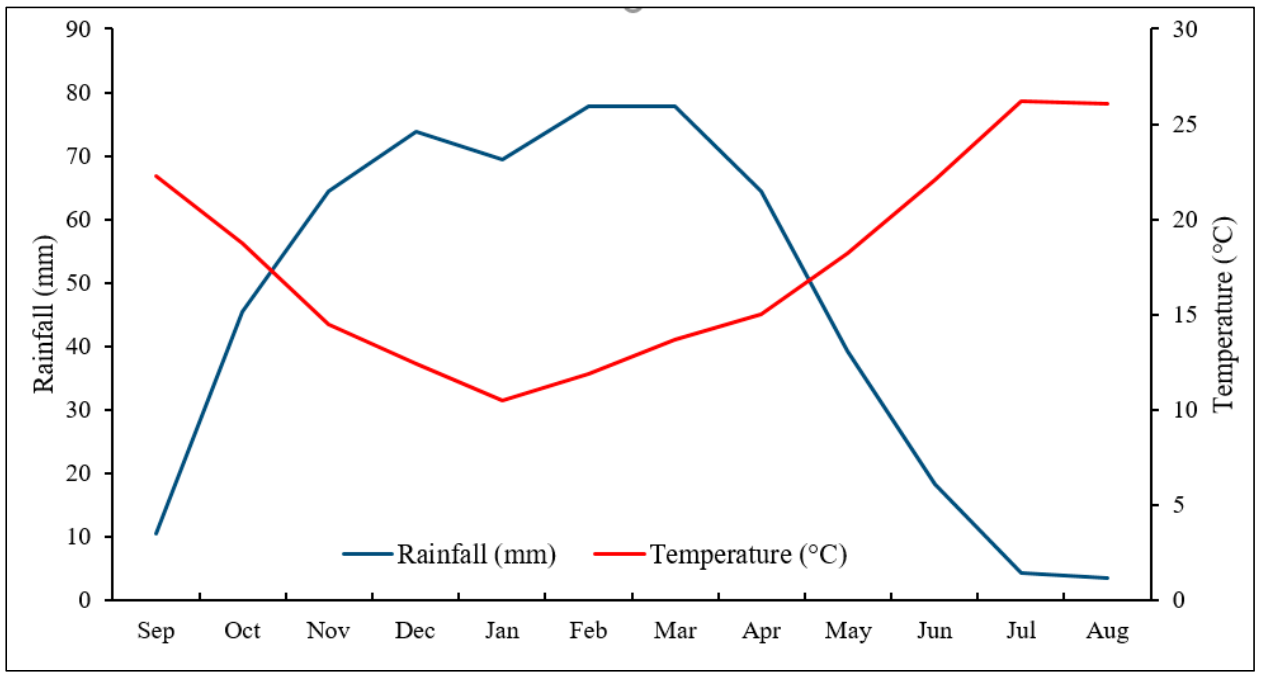

Figure 2. Ombrothermic diagram of the meteorological station at Meknes. Rainfall is mean monthly rain depth and temperature is mean monthly air temperature (1998-2018).

\subsection{Data}

The regions of interest used for land use classification were developed based on a series of field missions throughout the study area along with high-resolution Google Earth visualizations. A total of 88,546 pixels with a resolution of $10 \mathrm{~m}^{2}$ was used for classification; $65 \%$ were used as reference data and $35 \%$ for the validation. The sampling was done in a random way; it was chosen to be representative and well distributed in the area. Figure 3 shows the field data used for this work. Weather data were collected for the study period of September 2018 to August 2019. These data included monthly mean rainfall, monthly average minimum temperature, monthly average maximum temperature, humidity (\%), wind speed $(\mathrm{m} / \mathrm{s})$, and sunshine intensity (hours). Figure 4 shows climate data collected by the climate station at the Faculty of Science of Meknes, Moulay Ismail University, coordinates: Latitude: $33^{\circ} 52^{\prime} 11.12^{\prime \prime} \mathrm{N}$, Longitude: $5^{\circ} 32^{\prime} 35.11^{\prime \prime} \mathrm{W}, \mathrm{Z}=554 \mathrm{~m}$.

For the satellite data, a total of 13 satellite images covering a whole crop year were used to carry out this work. All these images were obtained from the Sentinel-2 sensor of the European Space Agency (https:/ / sentinel.esa.int/web/sentinel/sentinel-data-access (accessed on 15 August 2021)). This mission was launched in June 2015, with a revisit time (i.e., image interval) of 10 days and image spatial resolution of $10 \mathrm{~m}$ to $60 \mathrm{~m}$ in thirteen spectral bands from visible to mid-infrared. Images were downloaded from https://scihub.copernicus.eu/dhus/\#/home (accessed on 15 August 2021) for the period August 2018-August 2019 (Table 1).

Table 1. Sentinel-2 satellite image acquisition dates.

\begin{tabular}{cc}
\hline Image & Acquisition Dates \\
\hline 1 & 22 August 2018 \\
2 & 1 September 2018 \\
3 & 21 October 2018 \\
4 & 15 November 2018 \\
5 & 15 December 2018 \\
6 & 14 January 2019 \\
7 & 13 February 2019 \\
8 & 15 March 2019 \\
9 & 29 April 2019 \\
10 & 14 May 2019 \\
11 & 8 June 2019 \\
12 & 18 July 2019 \\
13 & 22 August 2019 \\
\hline
\end{tabular}




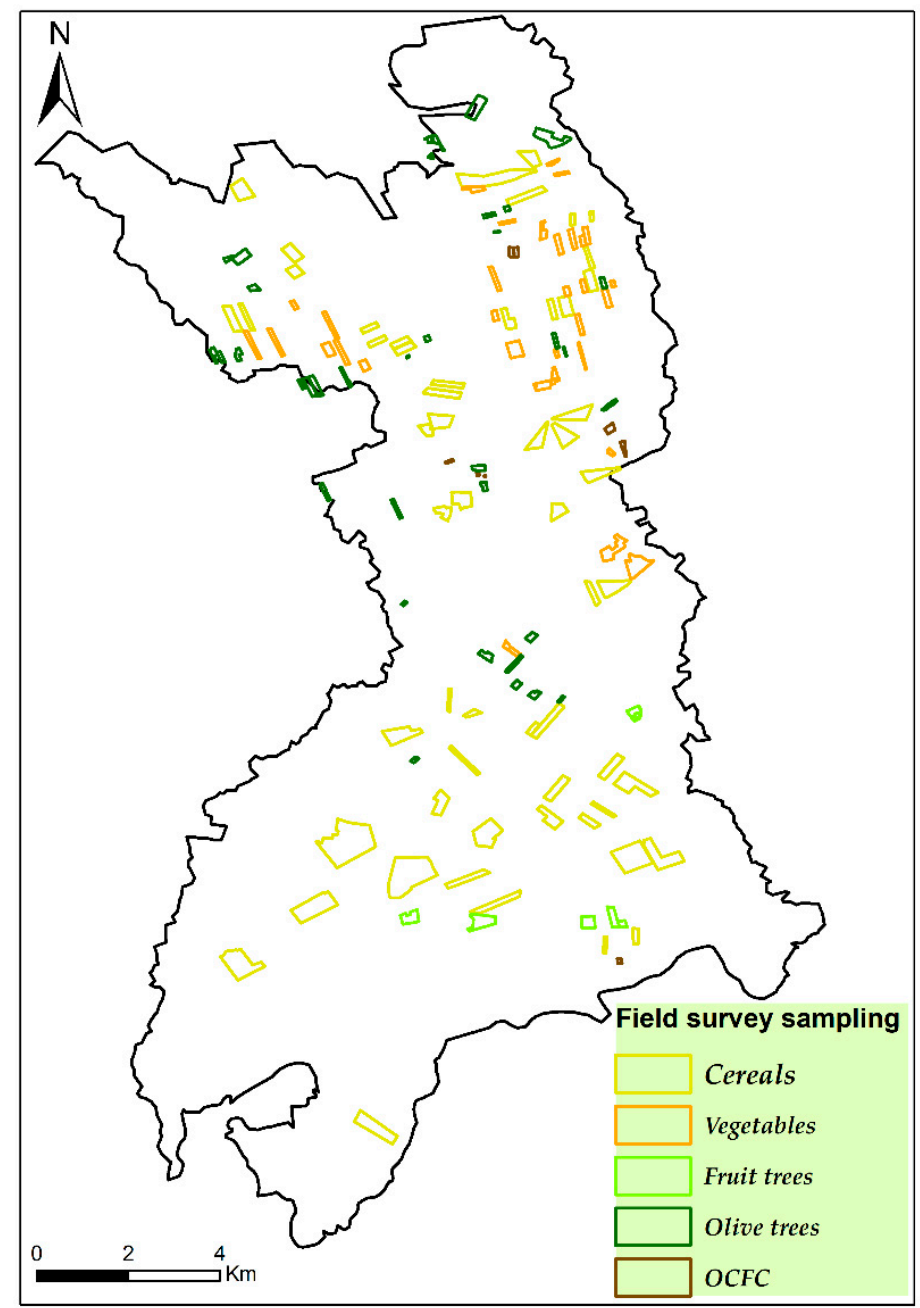

Figure 3. Field survey sampling. OCFC: Other crops follow by cereals.

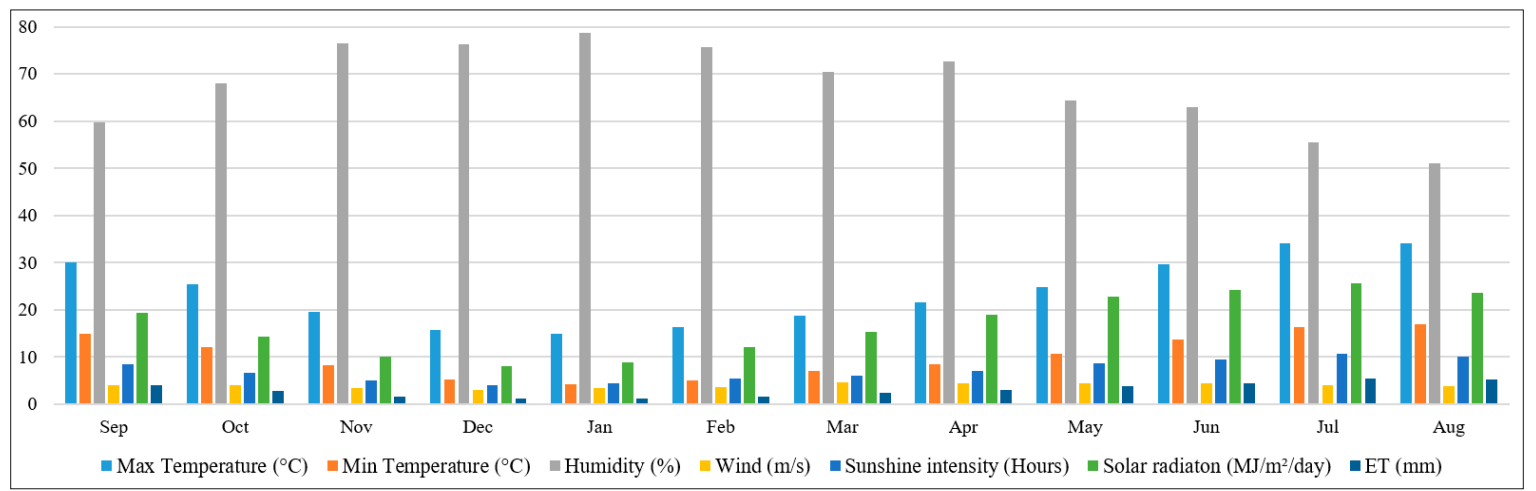

Figure 4. Climatic data.

\subsection{Methodolgy}

Normalized difference vegetation index (NDVI) was calculated to construct NDVI time-series images. In parallel, several surveys and field missions were conducted in the region to collect reference (validation) points for the different agricultural crops. These data were combined with the high spatial resolution Google Earth images. Spectral profiles were then constructed and used as input data for a machine learning approach to map different crop species in the region. As a final step, and to associate satellite data with observed water management practices, CROPWAT 8.0 software was used to estimate crop water 
requirements (Figure 5). The simulation was carried out on three parameters: potential evapotranspiration for the different crop types (ETc), effective rainfall (ER), and irrigation water requirements (IWR). These three parameters are dependent on each other. The ETc is the amount of water that should be transpired in a given time by the crop, while the ER is defined as the rainfall fraction that responds to the crops' water needs [43]. During the rainy months, rainfall covers the water requirements of the crops, while during the dry months, rainfall must be supplemented by irrigation water to cover water requirements.

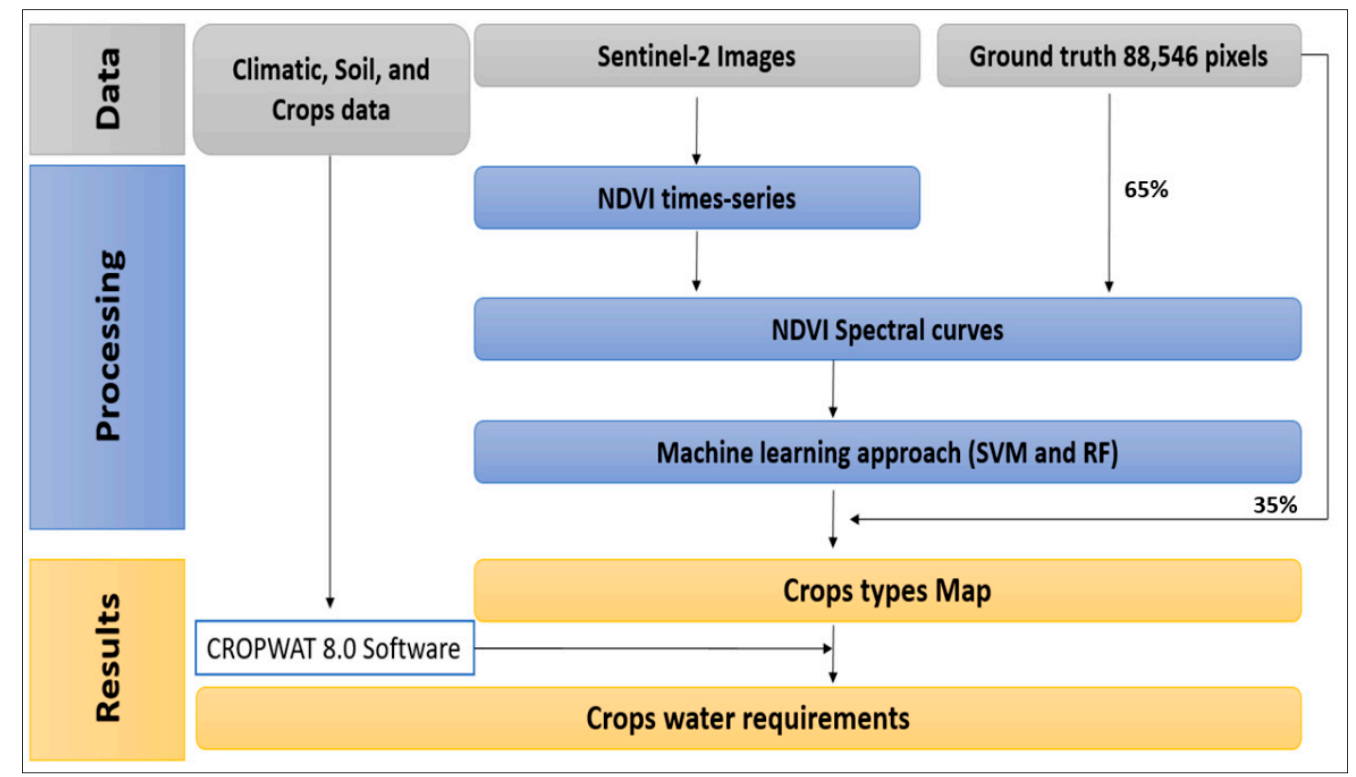

Figure 5. Flowchart of the methodology.

\subsection{Support Vector Machine (SVM)}

SVMs belong to a family of algorithms that use supervised learning and are specialized in solving mathematical discrimination and regression problems. They were developed in 1998 by Vladimir Vapnik [44]. Support vector machines (SVMs) represent a group of theoretically superior machine learning algorithms. The development of this method was initially triggered by the exploration and formalization of machine learning capacity control and over-fitting problems [44] and represents an efficient technique, with reduced data and processing demands. The method avoids the problems of over-adjustment and does not require any hypothesis on the type of data. Although non-parametric, the method is capable of developing efficient decision limits and can therefore minimize classification errors. This is done by searching for the optimal separation between classes [45]. Their work was quickly adopted because of their ability to work with large data, their theoretical guarantees and the good results achieved in practice. Requiring a small number of parameters, SVMs are appreciated for their simplicity of use.

\subsection{Random Forest (RF) Classifier}

Random forest (RF) was developed by [46]. It is a supervised non-parametric method applicable for both classification and prediction [47,48]. Model subroutines are composed of a combination of decision trees used independently to assign the most frequent class to the input data, and the majority vote of the trees determines the class prediction. The part of the data not used in tree training is used for performance evaluation.

For the current investigation, after extracting the crop type characteristic based on the data collected in the field, twelve decision trees were constructed and were the basis for RF classifier (Figure 6). These decision trees make it possible to predict the different classes. 


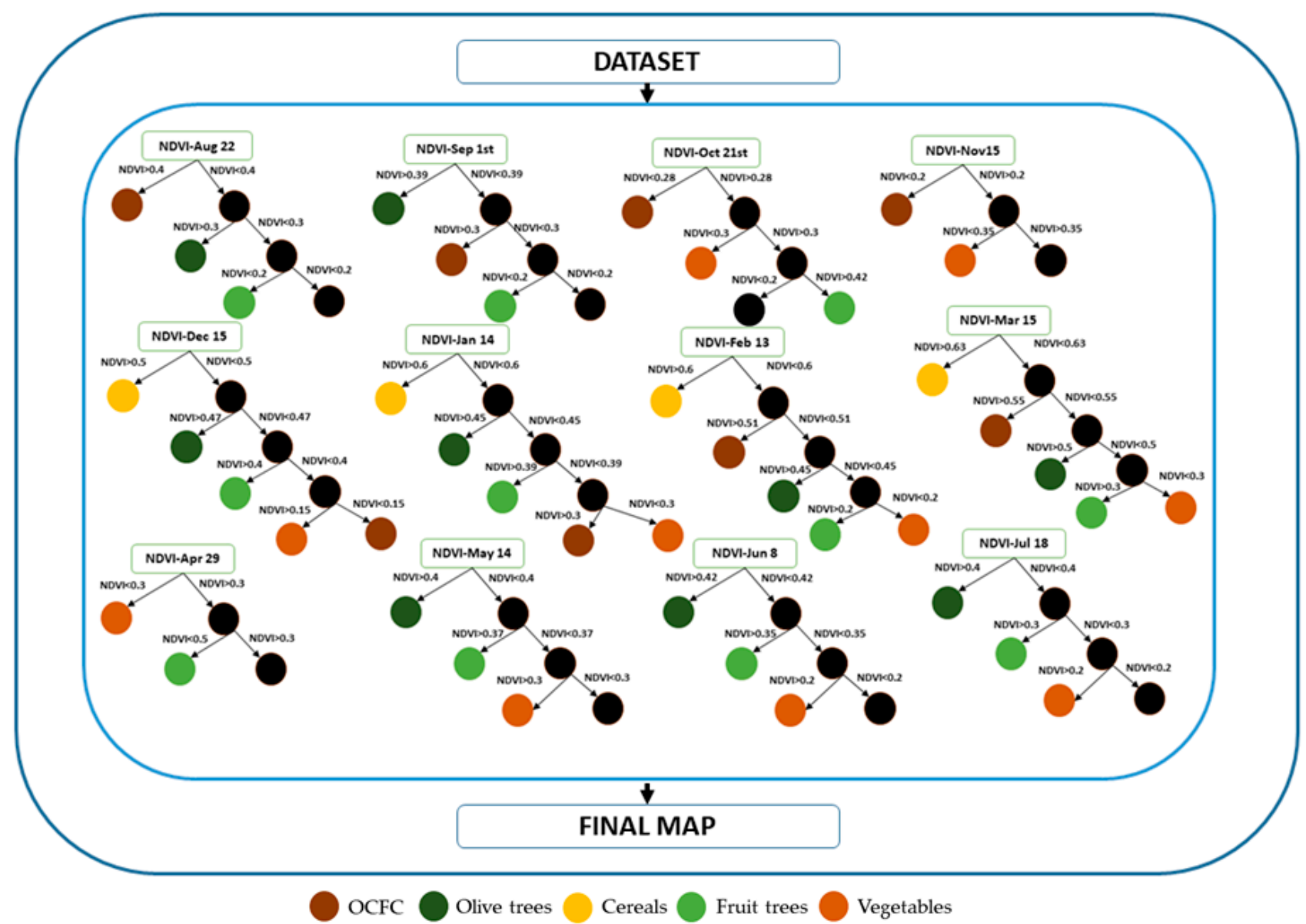

Figure 6. Decision trees used for random forest classification. OCFC = Other Crops Followed by Cereals.

\subsection{NDVI Time-Series Spectral Profile Curves}

Field data and data collected from the Regional Directorate of Agriculture showed the presence of five main cropping systems in the region, including cereals, other crops followed by cereals, vegetables (onion, potatoes, tomatoes), olive trees and fruit trees. More than two hundred profiles were developed for the different crop types. These profiles were associated with the field data and the visualization of high spatial resolution Google Earth images in order to collect input data for classification (Figures 7 and 8).

From Figure 8, it is possible to discriminate the spectral characteristics of the different crops in relation to NDVI values during the year. This index, proposed for the first time by Rouse et al., 1973 [49], is widely used and provides information on the quantity and vigor of vegetation, taking into account the near infrared (NIR) and visible red bands of the electromagnetic spectrum $[49,50]$ calculated by the following equation:

$$
N D V I=\rho_{N I R}-\rho_{R E D} / \rho_{N I R}+\rho_{R E D}
$$

where $\rho_{N I R}:$ the reflectance in the near - infrared reflectance, $\rho_{R E D}:$ the reflectance in the red band.

For example, for an olive pixel, the NDVI value did not change significantly throughout the year, with an increase around February. While for a pixel of cereals, the NDVI values did increase with the crop growth cycle. 

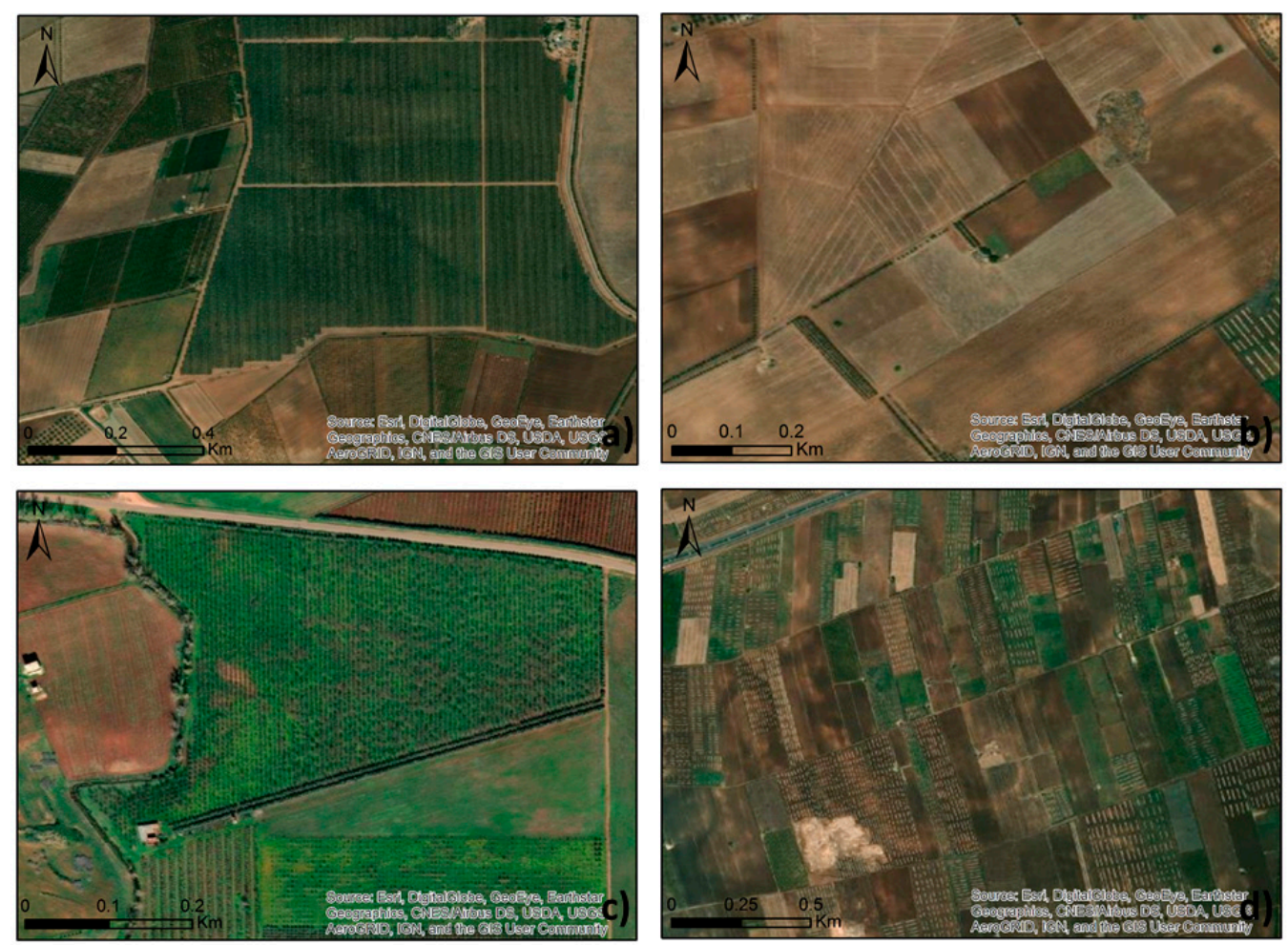

Figure 7. Different types of crops in the study area. (a) Olive trees, (b) Cereals, (c) Fruit trees, (d) Vegetables (Source: Esri, Maxar, GeoEye, Earthstar Geographics, CNES/Airbus DS, USDA, USGS, AeroGRID, IGN, and the GIS User Community).

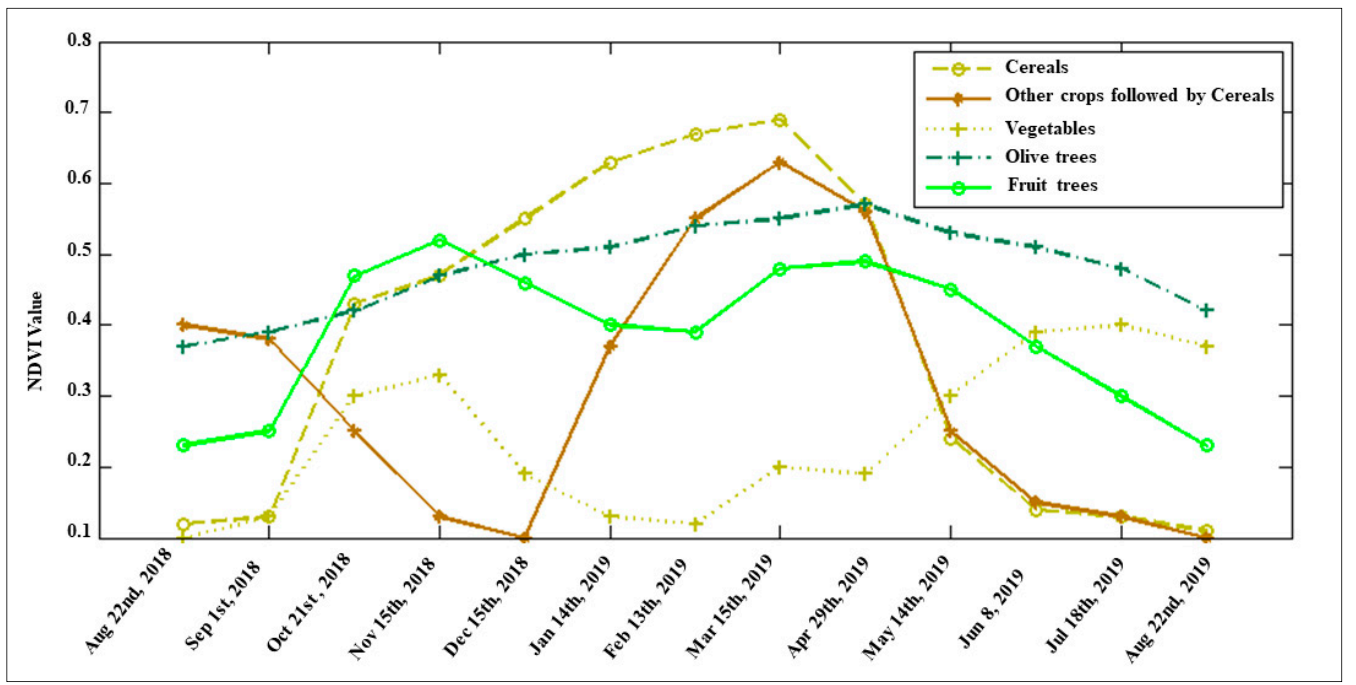

Figure 8. NDVI time-series spectral profile curves at different crop developmental stages.

\section{Results}

\subsection{Overall Accuracy}

The classification approaches used in this work were selected based on the confusion matrix and the Kappa index [51-53], whose the overall accuracy is the proportion of the area mapped correctly. It provides the user of the map with the probability that a randomly selected location on the map is correctly classified. The Kappa coefficient measures the agreement between the resulting classes of the classifier and the true values [52,54], with values ranging from 0 to 1 , where 0 represents no agreement and 1 represents perfect agreement. The Table 2 shows the confusion matrix calculated from the reference data 
and the map classes; the reference data is presented in the row, and the map classes in the columns. The results showed that the two approaches showed high classification accuracies. The overall accuracy for the SVM classifier exceeded $89.76 \%$, and a significant agreement by the Kappa index of 0.79 was obtained. The overall accuracy for RF was $84.03 \%$, with a Kappa index of 0.68 . For the validation, 57,554 pixels were used. In most cases, it showed a high accuracy of this classification for most crop species. Few confusions between classes were recorded using the RF approach (e.g., crops followed by cereals, cereals, vegetables, and olive trees).

Table 2. Confusion Matrix. OCFC = Other Crops Followed by Cereals.

\begin{tabular}{|c|c|c|c|c|c|c|c|c|c|c|c|c|}
\hline \multirow{3}{*}{$\begin{array}{c}\text { Map Classes } \\
\text { Classifier }\end{array}$} & \multicolumn{8}{|c|}{ Reference Data (\%) } & & & & \\
\hline & \multicolumn{2}{|c|}{ Cereals } & \multicolumn{2}{|c|}{ OCFC } & \multicolumn{2}{|c|}{ Vegetables } & \multicolumn{2}{|c|}{ Olive Trees } & \multicolumn{2}{|c|}{ Fruit Trees } & \multicolumn{2}{|c|}{ Total (\%) } \\
\hline & SVM & RF & SVM & RF & SVM & RF & SVM & RF & SVM & RF & SVM & RF \\
\hline Cereals & 88.23 & 87.40 & 6.05 & 24.43 & 2.05 & 1.52 & 1.21 & 5.17 & 0.65 & 6.17 & 64.17 & 64.32 \\
\hline OCFC & 5.27 & 4.48 & 88.10 & 41.86 & 4.80 & 10.76 & 1.66 & 7.39 & 0.48 & 0.62 & 5.54 & 5.81 \\
\hline Vegetables & 3.97 & 3.30 & 1.88 & 10.96 & 92.61 & 84.30 & 0.97 & 0.39 & 0.39 & 0.06 & 14.63 & 13.13 \\
\hline Olive trees & 2.20 & 3.41 & 3.76 & 13.47 & 0.43 & 0.88 & 94.79 & 70.05 & 2.36 & 23.69 & 11.42 & 10.79 \\
\hline \multirow[t]{2}{*}{ Fruit trees } & 0.33 & 1.40 & 0.21 & 9.29 & 0.11 & 2.53 & 1.37 & 17.01 & 96.13 & 69.46 & 4.23 & 5.94 \\
\hline & & & & & & & & & & & 100 & 100 \\
\hline
\end{tabular}

In addition to the overall accuracy and the Kappa index, other types of accuracy and errors were calculated for both classifiers, including the producer's accuracy, the user's accuracy, the commission error, and the omission error (Table 3) [53].

(i) Producer's accuracy is defined as the probability that a value in a reference dataset was correctly classified. Producer's accuracy is the complement to the probability of omission error.

(ii) User's accuracy represents the probability that a resulting value in a certain class is really that class. User's accuracy is the complement to the probability of commission error.

(iii) Commission errors represent the fraction of the resulting values in a class that does not belong to that class.

(iv) Omission errors represent the fraction of values that belongs to one class but was predicted in a different class.

Table 3. Commission, omission, producer's and user's accuracy for the SVM and RF classifiers.

\begin{tabular}{ccccccccc}
\hline Classes & \multicolumn{2}{c}{ Commission (\%) } & \multicolumn{2}{c}{ Omission (\%) } & \multicolumn{2}{c}{ Producer's Accuracy (\%) } & \multicolumn{2}{c}{ User's Accuracy (\%) } \\
\hline Classifier & SVM & RF & SVM & RF & SVM & RF & SVM & RF \\
\hline Cereals & 0.74 & 1.91 & 11.77 & 12.60 & 88.23 & 87.40 & 99.26 & 98.09 \\
OCFC & 82.93 & 92.26 & 11.90 & 58.14 & 88.10 & 41.86 & 17.07 & 7.74 \\
Vegetables & 20.49 & 19.38 & 7.39 & 15.70 & 92.61 & 84.30 & 79.51 & 80.62 \\
Olive trees & 15.56 & 33.95 & 5.21 & 29.95 & 94.79 & 70.05 & 84.44 & 66.05 \\
Fruit trees & 9.27 & 53.29 & 3.87 & 30.54 & 96.13 & 69.46 & 90.73 & 46.71 \\
\hline
\end{tabular}

In terms of accuracy, the producer's accuracy and user's accuracy confirm the results found for the overall accuracy. The producer's accuracy showed very high values, with more than $80 \%$ for all classes in the both classifiers SVM and RF, except the class other crops followed by cereals, which presented a value of $41.86 \%$ for the RF classifier. The user's accuracy showed very high values, with more than $79 \%$ for all classes in the SVM classifier, except for other crops followed by cereals, which presented a value $17.07 \%$. For the RF classifier, this accuracy shows high values for the three classes of cereals, vegetables, and olive trees: $98.09 \%, 80.62 \%$, and $66.05 \%$, respectively. The other two classes, fruit trees 
and other crops followed by cereals, represent low precision, with values of $46.71 \%$ and $7.74 \%$, respectively.

In terms of commission error, the results showed that the other crops followed by cereals represents the highest values for the two classifiers SVM and RF, with values of $82.93 \%$ and $92.26 \%$, respectively, followed by vegetables and fruit trees. The other two classes represented a low value for this error. For the omission error, cereals and other crops followed by cereals represented the highest value for the SVM, whereas for RF, cereals and other crops followed by cereals represent a high value of $58.14 \%$, followed by fruit trees with $30.54 \%$ and olive trees with $29.95 \%$.

\subsection{Crop Mapping}

Crop mapping was performed based on field data combined with a detailed study of the chlorophyll response (NDVI) for each of crop type. The crops determined in the region were cereals, other crops followed by cereals, vegetables (onions, potatoes, tomatoes), olive trees, and fruit trees. In order to calculate the areas of each class, pixel size was used. Therefore, after obtaining the classes, the area of each class was obtained by multiplying the number of pixels and the pixel size $(10 \mathrm{~m} \times 10 \mathrm{~m})$. For the crop year 2018-2019, the areas determined for the cereals represented the largest class, with an area of $8870.43 \mathrm{ha}$, followed by olive trees with an area of $4323.18 \mathrm{ha}$. Classes of other crops followed by cereals and vegetables represented 1661.45 ha and $1530.06 \mathrm{ha}$, respectively. The least represented class was that of fruit trees, with only 661.05 ha (Figure 9).
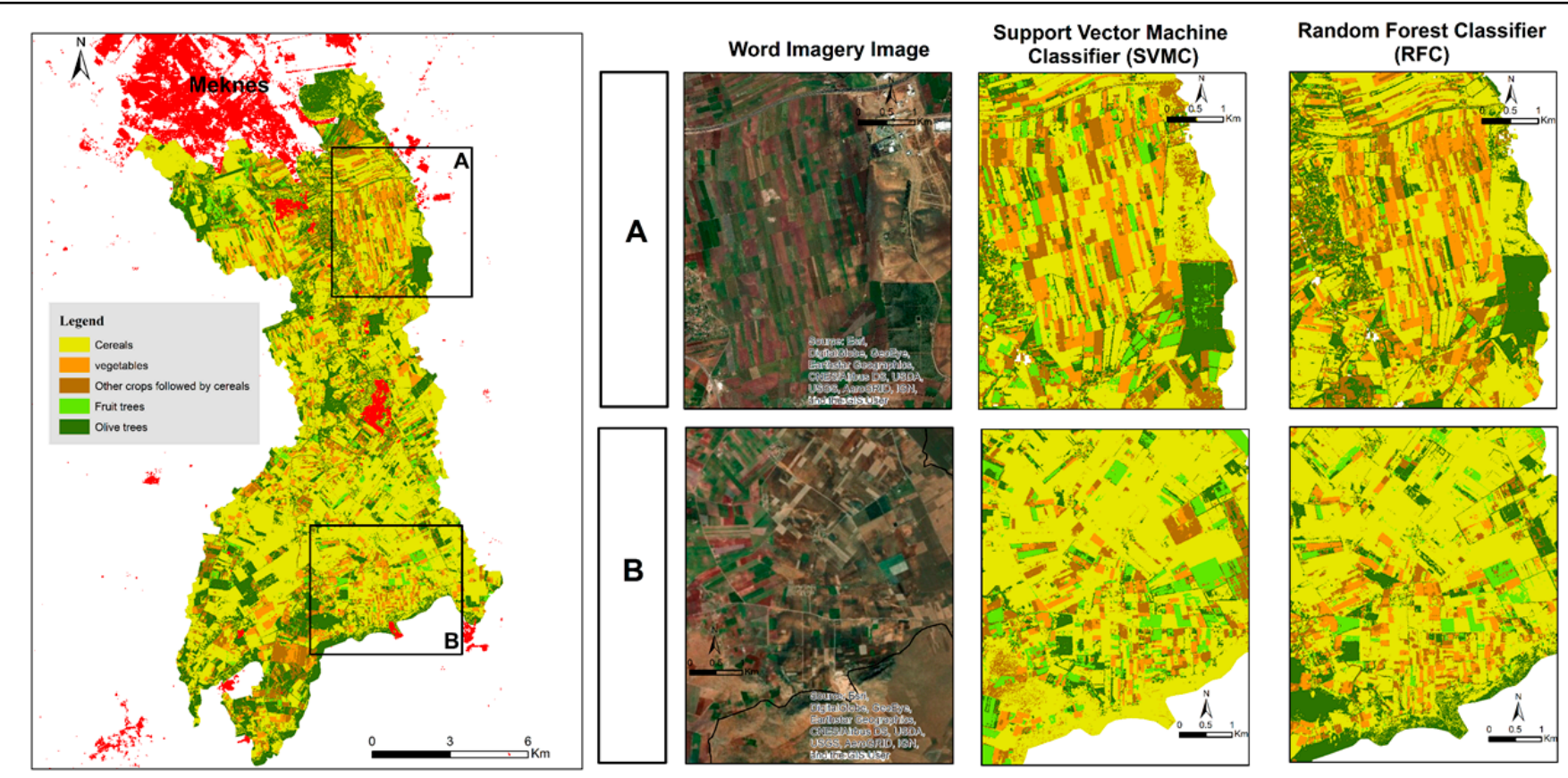

Figure 9. Crop mapping using SVM and RF classification. (A) Northern part (B) Southern part.

\subsection{CROPWAT for Water Crop Requirements}

This section includes calculation of the crop water requirements using the FAO free software CROPWAT 8.0, based on climate, soil, and crop data. Thus, three main variables were estimated by the units of water depth $(\mathrm{mm})$ : ETc, ER, and IWR. For preliminary planning, monthly data are frequently used, and the total of the data of the different crops over the area constitutes the basis for determining the supply.

The climatic data were used to calculate the reference evapotranspiration $\mathrm{ET}_{0}$, and by determining the timing of planting or sowing, the rate of crop development, the duration of crop development stages, and the growing season kc for a given crop were chosen. Then, 
the ETc for each crop type was calculated for each 10 day period. Figure 10 shows the different crop types' evapotranspiration from October 2018 to August 2019. The curves show that this parameter increases in the driest months (July and August) for all crop types, while it decreases in the rainiest months (December to February). For the class of other crops followed by cereals, for example, the potential evapotranspiration reached up to $70 \mathrm{~mm}$.

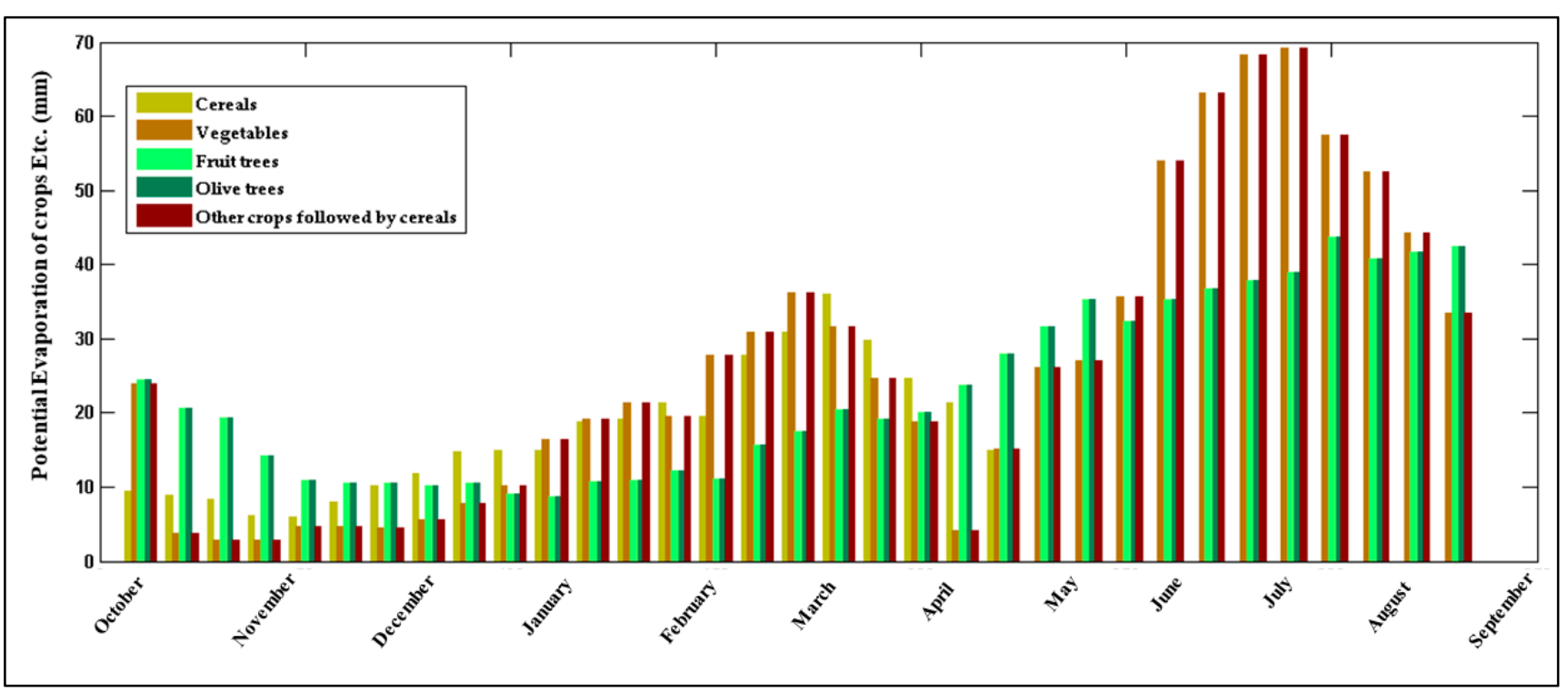

Figure 10. Potential evaporation of crops ETc.

Not all precipitation is effective, and in the most cases some of this precipitation can be lost through surface runoff, deep percolation, or evaporation. Only part of the high-intensity rain can penetrate and be stored in the root zone. These rains can be $100 \%$ effective when the vegetation cover is complete, while they can be only $60 \%$ effective with a low percentage of vegetation cover. The relationship between the average monthly ER and the average monthly rainfall is shown for different values of the average monthly ETc [55]. Figure 11 shows the evolution of ER for the different types of crops. The evolution curves of this parameter show that the crops' needs were met in the rainy months. However, in the dry months, these crops suffered from water stress.

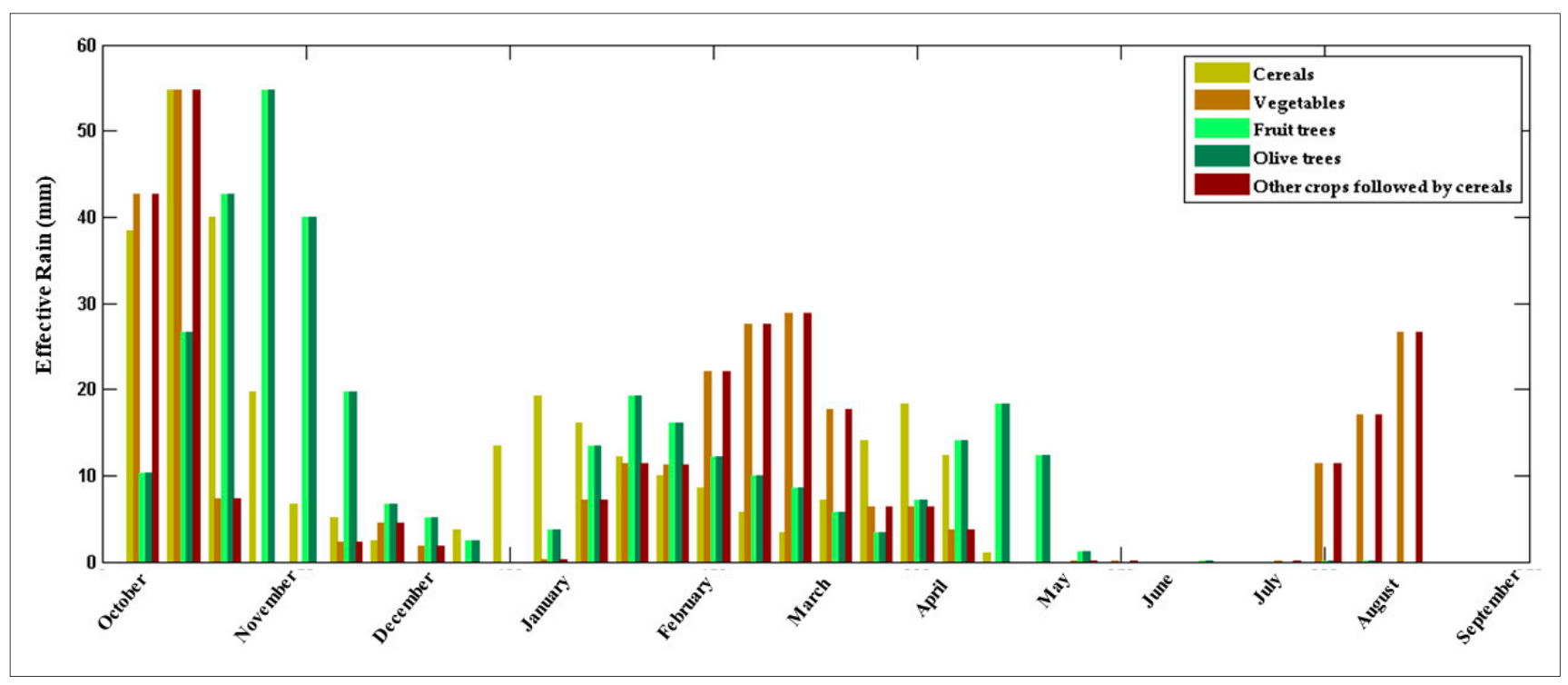

Figure 11. Effective rain. 
Irrigation water requirements are calculated using the field water balance, based on ETc and ER. They allow for optimal production in a given growing environment.

Figure 12 shows the evolution of water requirements for agriculture for the different types of crops. In the rainy months, rainfall covers the water requirements of the crops; during this time, the water requirements for irrigation are expected to be very low. This parameter is strongly related to the climatic conditions and is directly influenced by variations in conditions. It is inversely correlated with the daily rainfall. Thus, it is high in the dry months and low in the rainy months.

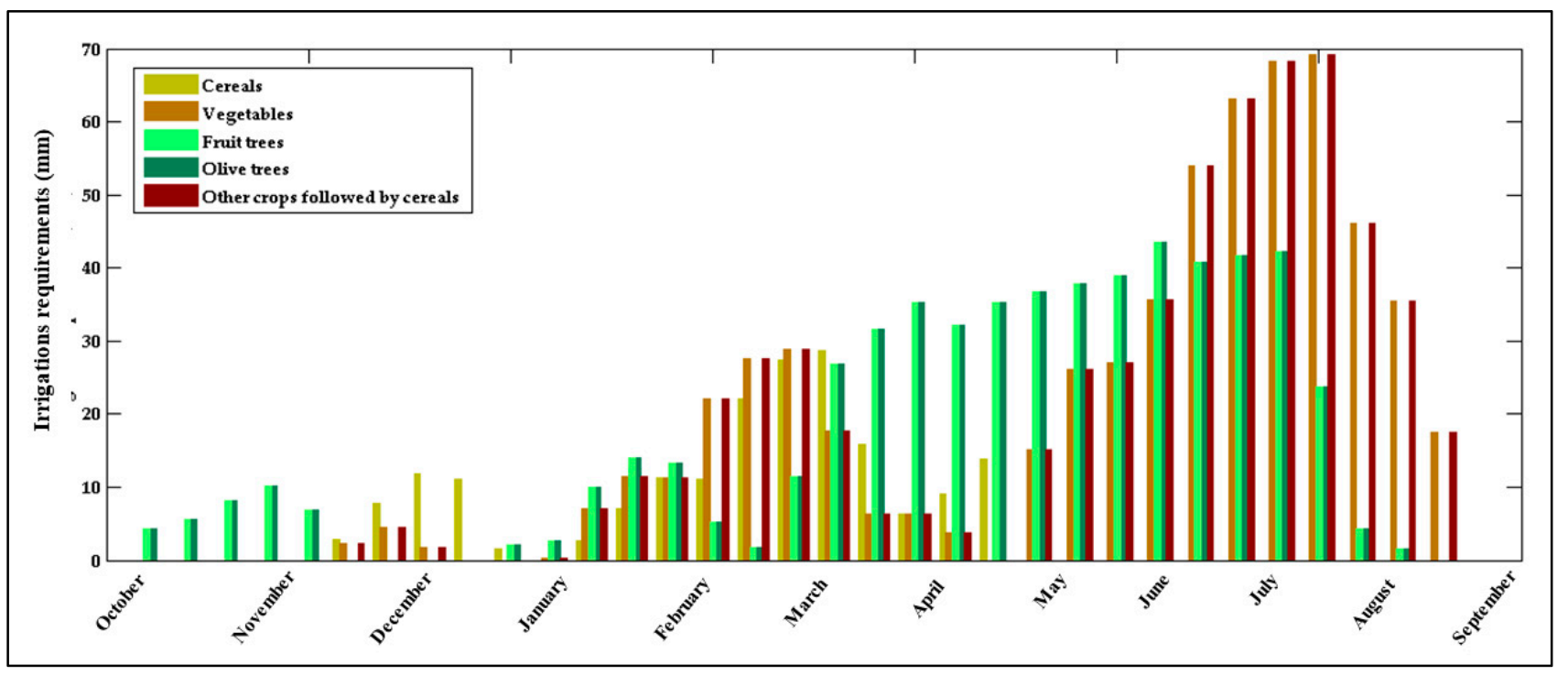

Figure 12. Irrigation requirements.

Figure 13 shows the total for the year of the three estimated parameters (ETc, ER, and IWR) for the different types of crops. For water irrigation requirements, other crops followed by cereals, olive trees, and fruit trees were the three types of crops that required a very large quantity of water, exceeding $500 \mathrm{~mm}$. Vegetables required about $450 \mathrm{~mm}$; the demand of cereals did not exceed $200 \mathrm{~mm}$. The potential evapotranspiration was strongly correlated with the water demand; the crop types that demanded a lot of water were those that recorded high values of evapotranspiration. For the ER, the class that recorded the lowest values was vegetables, while the other classes recorded values higher than $300 \mathrm{~mm}$.

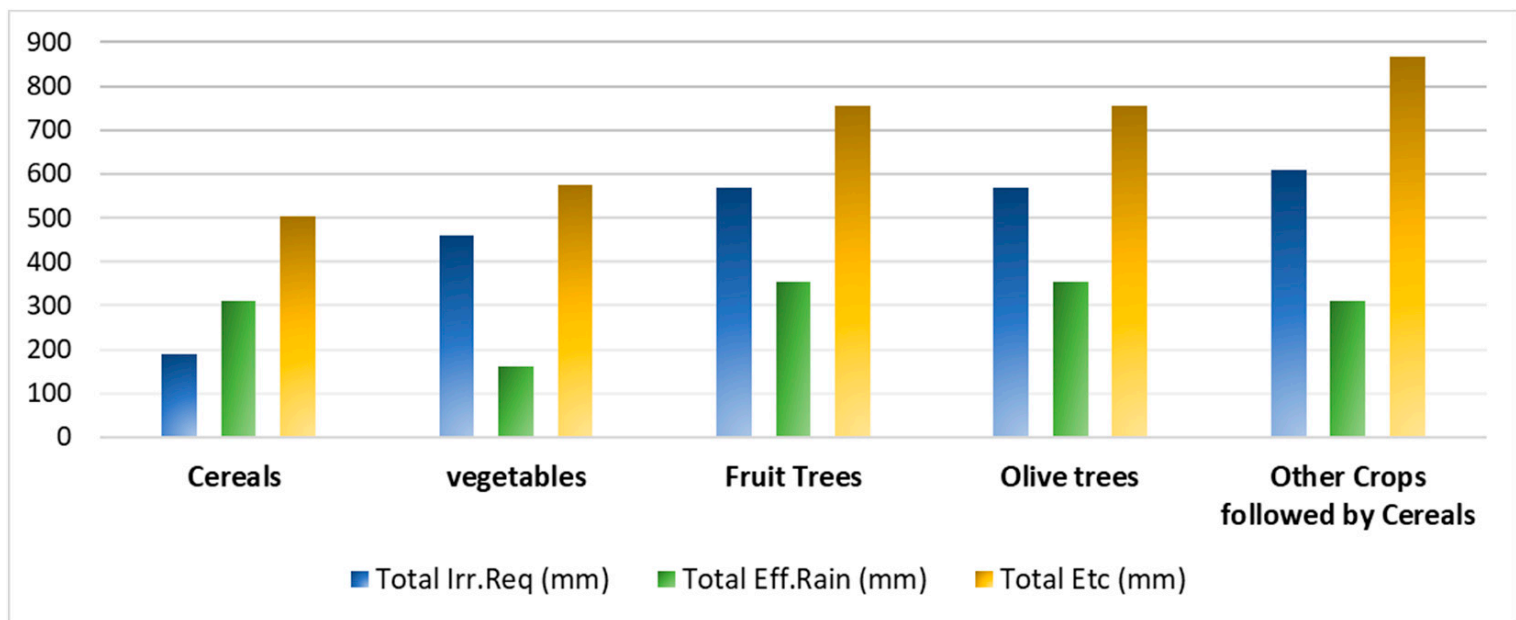

Figure 13. Total Etc, Eff.Rain, and Irr.Req. 


\section{Discussion}

Using the classification approach described earlier, and based on spectral analysis results, a map of the different agricultural species was produced for the study area (Figure 9). Results generally showed that the classification using both classifiers was satisfactory, with the exception of some confusion between a few classes, which is likely due to the spectral similarity of the crops.

Previous investigations using geospatial techniques have shown a strong efficiency in land use/land cover change monitoring [6,11], crop mapping [3,18], and identification of agricultural systems [8]. Ouzemou et al. [3] carried out an insightful study in the plains of Tadla, Morocco. The objectives included mapping different agricultural species using high-resolution satellite data and machine learning approaches and comparing the different used approaches. Their study showed an overall accuracy of $89.26 \%, 85.27 \%$, and $57.17 \%$, respectively, for random forest, support vector machine, and spectral angle mapper, with a Kappa index of $0.85,0.80$, and 0.4 , respectively. Comparing our result with this one, our study also showed a high overall accuracy of $89.76 \%$ for SVM and $84.03 \%$ for RF, and a Kappa index of 0.79 and 0.68 , respectively.

The CROPWAT model was used to determine water demand for the different agricultural species in the region. Three parameters were calculated, namely, the crops' potential evaporation, the effective rain, and the irrigation requirements. The results obtained by [40] showed that the irrigation requirements varied according to the location, whereas the required water quantity per palm varied between 115 and 200 liters per day. Comparing our result with this one, our study showed that olive trees, fruit trees, and other crops followed by cereals are the most water demanding, with needs exceeding $500 \mathrm{~mm}$. The water demands of cereals and vegetables are lower than that of other classes, with amounts of $300 \mathrm{~mm}$ and $150 \mathrm{~mm}$, respectively.

As explained, water consumption is increasing in the Saiss plain. This is mainly due to excessive exploitation. According to the 1939-2002 groundwater data record, there is a constant deficit of approximately $100 \mathrm{Mm}^{3}$ /year, with an estimated inflow of $242 \mathrm{Mm}^{3} /$ year and an estimated outflow of $342 \mathrm{Mm}^{3} /$ year. While the output includes abstraction with $260 \mathrm{Mm}^{3}$ /year, and rivers and springs with $82 \mathrm{Mm}^{3} /$ year, $22 \%$ of the water balance is dedicated to human drinking water supplies and $78 \%$ to private irrigation [56].

\section{Conclusions}

The assessment and estimation of water demand for agriculture is crucial to improve water resource management in a given region. The final objective was to determine the water demand for agriculture in the Boufakrane River watershed through several steps. First, a map of the different crop types was produced using the SVM and RF machine learning algorithms, based on field data combined with the high spatial resolution Google Earth images. Five crop types were mapped, including cereals, other crops followed by cereals, vegetables, olive trees, and fruit trees. Then, the evaluation of the classification map was made based on the Kappa index and the overall accuracy. Finally, the satellite data were combined with climate, soil, and crop data before being used as inputs for CROPWAT software to estimate the water requirements for agriculture.

The mapping results showed a strong potential of high-resolution satellite data in agricultural species mapping. The evaluation of the two classifiers used (RF and SVM) showed a Kappa index higher than 0.67 and an overall accuracy exceeding $83 \%$. The irrigation requirements showed that the other crops followed by cereals, olive trees, and fruit trees were the three types of crops that required a very large quantity of water, exceeding $500 \mathrm{~mm}$. Vegetables required an amount of about $450 \mathrm{~mm}$; the demand of cereals did not exceed $200 \mathrm{~mm}$.

The method developed in this work facilitates estimations of the agriculture water demand in the study area, thereby promoting sustainable water resource management. Through this study, we recommend a combination of these methods with existing real data for the implementation of a system for the quantification of water resources for 
crops throughout Morocco, which would allow validation using global crop yield data. It was also an opportunity to see the link between water demand and known groundwater reserves and existing data on actual evapotranspiration in this area.

Author Contributions: Conceptualization, M.E.H., A.E. and A.V.R.; Data curation, M.E.H., A.E. and A.V.R.; Formal analysis, M.E.H., A.E. and A.V.R.; Funding acquisition, A.E. and A.V.R.; Investigation, A.E. and A.V.R.; Methodology, M.E.H., A.E. and A.V.R.; Project administration, A.E. and A.V.R.; Resources, A.E. and A.V.R.; Software, M.E.H.; Supervision, A.E. and A.V.R.; Validation, M.E.H., A.E. and A.V.R.; Visualization, M.E.H.; Writing-original draft, M.E.H., A.E. and A.V.R.; Writing-review and editing, M.E.H., K.F.-L. and J.A.H. All authors have read and agreed to the published version of the manuscript.

Funding: This research received no external funding.

Institutional Review Board Statement: Not Applicable.

Informed Consent Statement: Not Applicable.

Acknowledgments: The authors would like to thank the Thematic Project 4, Integrated Water Resources Management of the Institutional University Cooperation, and VLIR-UOS for the financial support, equipment and mission at KU Leuven, Belgium.

Conflicts of Interest: The authors declare no conflict of interest.

\section{References}

1. Beckers, V.; Poelmans, L.; Van Rompaey, A.; Dendoncker, N. The Impact of Urbanization on Agricultural Dynamics: A Case Study in Belgium. J. Land Use Sci. 2020, 15, 626-643. [CrossRef]

2. Mazoyer, M.; Roudart, L. A History of World Agriculture: From the Neolithic Age to the Current Crisis; NYU Press: Manhattan, NY, USA, 2006.

3. Ouzemou, J.-E.; El Harti, A.; Lhissou, R.; El Moujahid, A.; Bouch, N.; El Ouazzani, R.; Bachaoui, E.M.; El Ghmari, A. Crop Type Mapping from Pansharpened Landsat 8 NDVI Data: A Case of a Highly Fragmented and Intensive Agricultural System. Remote Sens. Appl. Soc. Environ. 2018, 11, 94-103. [CrossRef]

4. Almazroui, M.; Nazrul Islam, M.; Saeed, S.; Alkhalaf, A.K.; Dambul, R. Assessment of Uncertainties in Projected Temperature and Precipitation over the Arabian Peninsula Using Three Categories of Cmip5 Multimodel Ensembles. Earth Syst. Environ. 2017, 1, 1-20. [CrossRef]

5. Driouech, F.; Déqué, M.; Sánchez-Gómez, E. Weather Regimes-Moroccan Precipitation Link in a Regional Climate Change Simulation. Glob. Planet. Chang. 2010, 72, 1-10. [CrossRef]

6. El Hafyani, M.; Essahlaoui, A.; Van Rompaey, A.; Mohajane, M.; El Hmaidi, A.; El Ouali, A.; Moudden, F.; Serrhini, N.-E. Assessing Regional Scale Water Balances through Remote Sensing Techniques: A Case Study of Boufakrane River Watershed, Meknes Region, Morocco. Water 2020, 12, 320. [CrossRef]

7. El Moçayd, N.; Kang, S.; Eltahir, E.A.B. Climate Change Impacts on the Water Highway Project in Morocco. Hydrol. Earth Syst. Sci. 2020, 24, 1467-1483. [CrossRef]

8. Lebrini, Y.; Boudhar, A.; Hadria, R.; Lionboui, H.; Elmansouri, L.; Arrach, R.; Ceccato, P.; Benabdelouahab, T. Identifying Agricultural Systems Using SVM Classification Approach Based on Phenological Metrics in a Semi-Arid Region of Morocco. Earth Syst. Environ. 2019, 3, 277-288. [CrossRef]

9. Barakat, A.; Ouargaf, Z.; Khellouk, R.; El Jazouli, A.; Touhami, F. Land Use/Land Cover Change and Environmental Impact Assessment in Béni-Mellal District (Morocco) Using Remote Sensing and GIS. Earth Syst. Environ. 2019, 3, 113-125. [CrossRef]

10. Mohajane, M.; Essahlaoui, A.; Oudija, F.; El Hafyani, M.; Hmaidi, A.E.; El Ouali, A.; Randazzo, G.; Teodoro, A.C. Land Use/Land Cover (LULC) Using Landsat Data Series (MSS, TM, ETM+ and OLI) in Azrou Forest, in the Central Middle Atlas of Morocco. Environments 2018, 5, 131. [CrossRef]

11. Rogan, J.; Chen, D. Remote Sensing Technology for Mapping and Monitoring Land-Cover and Land-Use Change. Prog. Plan. 2004, 61, 301-325. [CrossRef]

12. Sciortino, M.; De Felice, M.; De Cecco, L.; Borfecchia, F. Remote Sensing for Monitoring and Mapping Land Productivity in Italy: A Rapid Assessment Methodology. CATENA 2020, 188, 104375. [CrossRef]

13. Wu, Q.; Li, H.; Wang, R.; Paulussen, J.; He, Y.; Wang, M.; Wang, B.; Wang, Z. Monitoring and Predicting Land Use Change in Beijing Using Remote Sensing and GIS. Landsc. Urban Plan. 2006, 78, 322-333. [CrossRef]

14. Zhang, Y.; Ye, A. Spatial and Temporal Variations in Vegetation Coverage Observed Using AVHRR GIMMS and Terra MODIS Data in the Mainland of China. Int. J. Remote Sens. 2020, 41, 4238-4268. [CrossRef]

15. Randazzo, G.; Cascio, M.; Fontana, M.; Gregorio, F.; Lanza, S.; Muzirafuti, A. Mapping of Sicilian Pocket Beaches Land Use/Land Cover with Sentinel-2 Imagery: A Case Study of Messina Province. Land 2021, 10, 678. [CrossRef] 
16. Gerard, F.; Petit, S.; Smith, G.; Thomson, A.; Brown, N.; Manchester, S.; Wadsworth, R.; Bugar, G.; Halada, L.; Bezák, P.; et al. Land Cover Change in Europe between 1950 and 2000 Determined Employing Aerial Photography. Prog. Phys. Geogr. 2010, 34, 183-205. [CrossRef]

17. Tavares, P.A.; Beltrão, N.; Guimarães, U.S.; Teodoro, A.; Gonçalves, P. Urban Ecosystem Services Quantification through Remote Sensing Approach: A Systematic Review. Environments 2019, 6, 51. [CrossRef]

18. Waldhoff, G.; Lussem, U.; Bareth, G. Multi-Data Approach for Remote Sensing-Based Regional Crop Rotation Mapping: A Case Study for the Rur Catchment, Germany. Int. J. Appl. Earth Obs. Geoinf. 2017, 61, 55-69. [CrossRef]

19. Wu, M.; Huang, W.; Niu, Z.; Wang, Y.; Wang, C.; Li, W.; Hao, P.; Yu, B. Fine Crop Mapping by Combining High Spectral and High Spatial Resolution Remote Sensing Data in Complex Heterogeneous Areas. Comput. Electron. Agric. 2017, 139, 1-9. [CrossRef]

20. Yue, J.; Tian, Q. Estimating Fractional Cover of Crop, Crop Residue, and Soil in Cropland Using Broadband Remote Sensing Data and Machine Learning. Int. J. Appl. Earth Obs. Geoinf. 2020, 89, 102089. [CrossRef]

21. Boualoul, M.; Randazzo, G.; Lanza, S.; Allaoui, A.; Ouardi, H.E.; Habibi, H.; Ouhaddach, H. The use of remote sensing for water protection in the karst environment of the Tabular Middle Atlas/the causse of El Hajeb/Morocco. In Proceedings of the IX Conference of the Italian Society of Remote Sensing, Firenze, Italy, 30 November-1 December 2018; Volume 2000 , p. 16.

22. Muzirafuti, A.; Boualoul, M.; Barreca, G.; Allaoui, A.; Bouikbane, H.; Lanza, S.; Crupi, A.; Randazzo, G. Fusion of Remote Sensing and Applied Geophysics for Sinkholes Identification in Tabular Middle Atlas of Morocco (the Causse of El Hajeb): Impact on the Protection of Water Resource. Resources 2020, 9, 51. [CrossRef]

23. Ouardi, H.E.; Boualoul, M.; Ouhaddach, H.; Habibi, M.; Muzarafuti, A.; Allaoui, A.; Amine, A. Fault Analysis and Its Relationship with Karst Structures Affecting Lower Jurassic Limestones in the Agourai Plateau (Middle Atlas, Morocco). Geogaceta 2018, 63, 119-122.

24. Wieland, M.; Martinis, S. Large-Scale Surface Water Change Observed by Sentinel-2 during the 2018 Drought in Germany. Int. J. Remote Sens. 2020, 41, 4742-4756. [CrossRef]

25. Bachri, I.; Hakdaoui, M.; Raji, M.; Teodoro, A.C.; Benbouziane, A. Machine Learning Algorithms for Automatic Lithological Mapping Using Remote Sensing Data: A Case Study from Souk Arbaa Sahel, Sidi Ifni Inlier, Western Anti-Atlas, Morocco. ISPRS Int. J. Geo-Inf. 2019, 8, 248. [CrossRef]

26. Du, P.; Tan, K.; Xing, X. Wavelet SVM in Reproducing Kernel Hilbert Space for Hyperspectral Remote Sensing Image Classification. Opt. Commun. 2010, 283, 4978-4984. [CrossRef]

27. Liu, Y.; Zhang, B.; Wang, L.; Wang, N. A Self-Trained Semisupervised SVM Approach to the Remote Sensing Land Cover Classification. Comput. Geosci. 2013, 59, 98-107. [CrossRef]

28. Maulik, U.; Chakraborty, D. A Self-Trained Ensemble with Semisupervised SVM: An Application to Pixel Classification of Remote Sensing Imagery. Pattern Recognit. 2011, 44, 615-623. [CrossRef]

29. Mohajane, M.; Costache, R.; Karimi, F.; Bao Pham, Q.; Essahlaoui, A.; Nguyen, H.; Laneve, G.; Oudija, F. Application of Remote Sensing and Machine Learning Algorithms for Forest Fire Mapping in a Mediterranean Area. Ecol. Indic. 2021, $129,107869$. [CrossRef]

30. Fathizad, H.; Ali Hakimzadeh Ardakani, M.; Sodaiezadeh, H.; Kerry, R.; Taghizadeh-Mehrjardi, R. Investigation of the Spatial and Temporal Variation of Soil Salinity Using Random Forests in the Central Desert of Iran. Geoderma 2020, 365, 114233. [CrossRef]

31. Iqbal, F.; Lucieer, A.; Barry, K. Poppy Crop Capsule Volume Estimation Using UAS Remote Sensing and Random Forest Regression. Int. J. Appl. Earth Obs. Geoinf. 2018, 73, 362-373. [CrossRef]

32. Izquierdo-Verdiguier, E.; Zurita-Milla, R. An Evaluation of Guided Regularized Random Forest for Classification and Regression Tasks in Remote Sensing. Int. J. Appl. Earth Obs. Geoinf. 2020, 88, 102051. [CrossRef]

33. Bekele, A.A.; Pingale, S.M.; Hatiye, S.D.; Tilahun, A.K. Impact of Climate Change on Surface Water Availability and Crop Water Demand for the Sub-Watershed of Abbay Basin, Ethiopia. Sustain. Water Resour. Manag. 2019, 5, 1859-1875. [CrossRef]

34. Birhanu, A.; Murlidhar Pingale, S.; Soundharajan, B.; Singh, P. GIS-Based Surface Irrigation Potential Assessment for Ethiopian River Basin. Irrig. Drain. 2019, 68, 607-616. [CrossRef]

35. Grammatikopoulou, I.; Sylla, M.; Zoumides, C. Economic Evaluation of Green Water in Cereal Crop Production: A Production Function Approach. Water Resour. Econ. 2020, 29, 100148. [CrossRef]

36. Lee, S.K.; Dang, T.A. Predicting the Water Use-Demand as a Climate Change Adaptation Strategy for Rice Planting Crops in the Long Xuyen Quadrangle Delta. Paddy Water Environ. 2019, 17, 561-570. [CrossRef]

37. Paymard, P.; Yaghoubi, F.; Nouri, M.; Bannayan, M. Projecting Climate Change Impacts on Rainfed Wheat Yield, Water Demand, and Water Use Efficiency in Northeast Iran. Theor. Appl. Climatol. 2019, 138, 1361-1373. [CrossRef]

38. Ruan, H.; Yu, J.; Wang, P.; Wang, T. Increased Crop Water Requirements Have Exacerbated Water Stress in the Arid Transboundary Rivers of Central Asia. Sci. Total Environ. 2020, 713, 136585. [CrossRef]

39. Severo Santos, J.F.; Naval, L.P. Spatial and Temporal Dynamics of Water Footprint for Soybean Production in Areas of Recent Agricultural Expansion of the Brazilian Savannah (Cerrado). J. Clean. Prod. 2020, 251, 119482. [CrossRef]

40. Surendran, U.; Sushanth, C.M.; Joseph, E.J.; Al-Ansari, N.; Yaseen, Z.M. FAO CROPWAT Model-Based Irrigation Requirements for Coconut to Improve Crop and Water Productivity in Kerala, India. Sustainability 2019, 11, 5132. [CrossRef]

41. Surendran, U.; Sushanth, C.M.; Mammen, G.; Joseph, E.J. Modelling the Crop Water Requirement Using FAO-CROPWAT and Assessment of Water Resources for Sustainable Water Resource Management: A Case Study in Palakkad District of Humid Tropical Kerala, India. Aquat. Procedia 2015, 4, 1211-1219. [CrossRef] 
42. Moseki, O.; Murray-Hudson, M.; Kashe, K. Crop Water and Irrigation Requirements of Jatropha curcas L. in Semi-Arid Conditions of Botswana: Applying the CROPWAT Model. Agric. Water Manag. 2019, 225, 105754. [CrossRef]

43. Brouwer, C.; Heibloem, M. Irrigation Water Management: Irrigation Water Needs. Train. Man. 1986, 3. Available online: https://www.fao.org/3/s2022e/s2022e00.htm (accessed on 20 August 2021).

44. Vapnik, V. The Support Vector Method of Function Estimation. In Nonlinear Modeling; Springer: Boston, MA, USA, 1998; pp. 55-85.

45. Bahari, N.I.S.; Ahmad, A.; Aboobaider, B.M. Application of Support Vector Machine for Classification of Multispectral Data. IOP Conf. Ser. Earth Environ. Sci. 2014, 20, 012038. [CrossRef]

46. Breiman, L. Random Forests. Mach. Learn. 2001, 45, 5-32. [CrossRef]

47. Costache, R.; Hong, H.; Pham, Q.B. Comparative Assessment of the Flash-Flood Potential within Small Mountain Catchments Using Bivariate Statistics and Their Novel Hybrid Integration with Machine Learning Models. Sci. Total Environ. 2020, $711,134514$. [CrossRef]

48. Nefeslioglu, H.A.; Sezer, E.; Gokceoglu, C.; Bozkir, A.S.; Duman, T.Y. Assessment of Landslide Susceptibility by Decision Trees in the Metropolitan Area of Istanbul, Turkey. Math. Probl. Eng. 2010, 2010, 1-15. [CrossRef]

49. Rouse, J.W., Jr. Monitoring the Vernal Advancement and Retrogradation of Natural Vegetation. NASA/GSFCT Type II Report, Greenbelt, MD, USA. 1973. Available online: https:/ / ntrs.nasa.gov/citations/19730020508 (accessed on 22 August 2021).

50. Rouse, J.W., Jr. Monitoring the Vernal Advancement and Retrogradation (Greenwave Effect) of Natural Vegetatioa NASA/GSFCT Type III Final Report, Greenbelt, MD, USA. 1974. Available online: https:/ / ntrs.nasa.gov/ citations/19740022555 (accessed on 22 August 2021).

51. Congalton, R.G. A Review of Assessing the Accuracy of Classifications of Remotely Sensed Data. Remote Sens. Environ. 1991, 37, 35-46. [CrossRef]

52. Stehman, S.V. Estimating the Kappa Coefficient and Its Variance under Stratified Random Sampling. Photogramm. Eng. Remote Sens. 1996, 62, 401-407.

53. Olofsson, P.; Foody, G.M.; Stehman, S.V.; Woodcock, C.E. Making Better Use of Accuracy Data in Land Change Studies: Estimating Accuracy and Area and Quantifying Uncertainty Using Stratified Estimation. Remote Sens. Environ. 2013, 129, 122-131. [CrossRef]

54. Foody, G.M. Explaining the Unsuitability of the Kappa Coefficient in the Assessment and Comparison of the Accuracy of Thematic Maps Obtained by Image Classification. Remote Sens. Environ. 2020, 239, 111630. [CrossRef]

55. Doorenbos, J.; Pruitt, W.O. Guidelines for Predicting Crop Water Requirements; FAO irrigation and drainage paper; Food and Agriculture Organization of the United Nations: Rome, Italy, 1977; ISBN 978-92-5-100279-7.

56. ABHS. Etude D'actualisation du Plan Directeurd'Aménagements Intégrés des Ressources en Eau (PDAIRE) du Bassin Hydraulique de Sebou; ABHS: Fez, Morocco, 2011. 